\title{
Monomeric and Dimeric (Aminomethylidene)phosphines and -Arsines
}

G. BECKER * , M. MAYER, O. MUNDT, H. RIFFEL, H.-J. WESSELY

Institut für Anorganische Chemie der Universität Stuttgart Pfaffenwaldring 55

A. SIMON

Max-Planck-Institut für Festkörperforschung

Heisenbergstr. 1

7000 stuttgart 80

In (dimethylaminomethylidene) phosphines (1) [1] and -arsines (2) the internal<smiles>[R]C=CN(C)C</smiles>

$E=P \underline{1}: E=A s \underline{2}$

$\mathrm{R}=\mathrm{C}\left(\mathrm{CH}_{3}\right)_{3} \underline{\mathrm{a}}$<smiles>[R]C1[C@H]([NH3+])[C@H]([R])[C@H]1[NH+](C)C</smiles>

$E=P \underline{3}: E=A s \underline{4}$<smiles>c1ccc2[nH]ccc2c1</smiles>

$E=P \underline{5} ; E=A s \underline{6}$

rotation of the dimethylamino group is hindered by a barrier of 50 to 55 $\mathrm{kJmol}^{-1}$ - analogous to the corresponding amidines. In order to evaluate the influence of this conjugative effect upon the $\mathrm{P}=\mathrm{C}$ and $(\mathrm{P})-\mathrm{C}-\mathrm{N}$ bond lengths, single crystal $x$-ray structure determinations of $\underline{1 a}$ and $\underline{2 a}$ have been carried out. For comparison, the cyclic (aminomethylidene)phosphine 1H-1,3-benzazaphosphole $\underline{5}$ [2] as well as the dimeric compounds $\underline{3 a}, \underline{3 b}$, and $\underline{3 c}$ [3] have been analyzed, too, while the arsenic derivative $\underline{6}$ was studied by others [4]. The diarsetanes 4 could not yet be isolated. The structural results indicate the $\mathrm{E}=\mathrm{C}$ bonds in $\underline{1 a}, \underline{2 a}, \underline{5}$, and $\underline{6}$ to be scarcely elongated, the (E) $-\mathrm{C}-\mathrm{N}$ bonds, however, to be shortened considerably with respect to the dimers.

[1] Becker, G.; Mundt, O.: Z. anorg. allg. Chem. 462 (1980) 130 ; Becker, G.; Uhl, W.; Wessely, H.-J.: ibid. 479 (1981) 41.

[2] Issleib, K.; Vollmer, R.: Z. anorg. allg. Chem. 481 (1981) 22.

[3] Becker, G.; Massa, W.; Mundt, O.; Schmidt, R.: Z. anorg. allg. Chem. $\underline{485}$ (1982) 23 .

[4] Richter, R.; Sieler, J.; Richter, A.; Heinicke, J.; Tzschach, A.; Lindqvist, o.: Z. anorg. allg. Chem. 501 (1983) 146. 